\begin{tabular}{|c|c|c|}
\hline $\begin{array}{l}\text { PKS } \\
\text { PUBLIC } \\
\text { KNDOLEDGE } \\
\text { PROJECT }\end{array}$ & $\begin{array}{c}\text { REVISTA DE GEOGRAFIA } \\
\text { (RECIFE) } \\
\text { nttp://www.revista.ufpe.br/revistageografia }\end{array}$ & $\begin{array}{l}\text { OJS } \\
\text { OPEN } \\
\text { JOUNAL } \\
\text { SYSTEMS }\end{array}$ \\
\hline
\end{tabular}

\title{
A IMPORTÂNCIA DO LEVANTAMENTO EXPEDITO DO USO DA TERRA E COBERTURA VEGETAL NAS DINÂMICAS DAS PAISAGENS DE PARTE DOS MUNICÍPIOS DE MARABÁ PAULISTA-SP E PRESIDENTE EPITÁCIO-SP
}

\author{
Melina Fushimi ${ }^{1}$, João Osvaldo Rodrigues Nunes ${ }^{2}$
}

\begin{abstract}
${ }^{1}$ Doutora em Geografia pelo Programa de Pós-Graduação em Geografia da Faculdade de Ciências e Tecnologia (UNESP), Câmpus de Presidente Prudente-SP. Email: melinafushimi@yahoo.com.br

${ }^{2}$ Docente do Programa de Pós-Graduação em Geografia da Faculdade de Ciências e Tecnologia (UNESP), Câmpus de Presidente Prudente-SP. Email: joaosvaldo@fct.unesp.br
\end{abstract}

Artigo recebido em 31/03/2017 e aceito em 24/09/2017

\begin{abstract}
RESUMO
No âmbito geográfico e das transformações aceleradas das paisagens urbanas e rurais têm-se os estudos que abordam e enfatizam a interpenetração das dinâmicas da sociedade e da natureza. Nesse sentido, o objetivo principal do presente artigo foi analisar a importância do levantamento expedito do uso da terra e cobertura vegetal nas dinâmicas das paisagens de parte dos municípios de Marabá Paulista-SP e Presidente Epitácio-SP. Para tal, foi elaborado o mapa de uso da terra e cobertura vegetal na escala 1:50.000 utilizando imagens de satélite ALOS/AVNIR-2, o qual subsidiou trabalhos de campo, em que quatro pontos representativos de amostragem foram caracterizados. De modo geral, a área de trabalho apresentou setores com matas ciliares e reflorestadas, solo exposto para posterior plantio de cana de açúcar, atividade canavieira e, principalmente, gramínea para pastagem. Tais classes, em interação com os demais aspectos que compõem as paisagens, refletem-se em meios estáveis, integrades e fortemente instáveis. Enfim, o trabalho pode contribuir ao orientar a implantação de medidas conservacionistas nos meios estáveis e técnicas de recuperação de áreas degradadas nos meios fortemente instáveis. Em relação aos meios intergrades, recomenda-se, a princípio, analisar o balanço pedogênese/morfogênese para, posteriormente, indicar quais práticas (conservação ou recuperação) poderão ser utilizadas.
\end{abstract}

Palavras-chave: Uso da terra. Cobertura Vegetal. Paisagens. Meios morfodinâmicos. Marabá Paulista-SP. Presidente Epitácio-SP.

\section{THE IMPORTANCE OF QUICK SURVEY OF LAND USE AND VEGETATION IN LANDSCAPES DYNAMICS IN PARTS OF MARABÁ PAULISTA-SP AND PRESIDENTE EPITÁCIO-SP}

\begin{abstract}
In geographic scope and the accelerated changes in urban and rural landscapes, there are the studies that address and emphasize the interpenetrating of society and nature dynamics. Therefore, this assignment aimed to analyze the importance of quick survey of land use and vegetation in landscapes dynamics in parts of Marabá Paulista-SP and Presidente Epitácio-SP. Thus, it was elaborated the land use and vegetation map in scale 1:50.000 using ALOS/AVNIR-2 imagery, which subsidized fieldwork, where four sampling points were characterized. In general, the study area presented sectors with ciliary and reforest forests, soil exposed to sugar cane planting, sugar cane planting and, especially, grass for pasture. These classes, interacting with the other landscape aspects,


result in stable, integrade and highly unstable units. Finally, the study may contribute to guiding the management of preventive measures in stable units and recovery techniques for degraded areas in highly unstable units. With respect to integrade units, it is recommended to analyze the balance of pedogenetic/morphogenetic processes to indicate which measures (conservation or recuperation) may be used.

Key-words: Land use. Vegetation. Landscapes. Morphodynamic units. Marabá Paulista-SP. Presidente EpitácioSP.

\section{INTRODUÇÃO}

No âmbito da ciência geográfica e das transformações aceleradas das paisagens urbanas e rurais, têm-se os estudos que abordam e enfatizam a interpenetração das dinâmicas da sociedade e das dinâmicas da natureza.

Dessa forma, supera-se a dicotomia entre Geografia Física e Geografia Humana ao integrar os atributos físico-naturais e humano-sociais nas análises dos fenômenos, bem como a articulação das reflexões teóricas e práticas.

A partir dessa perspectiva unificada por meio da relação sociedade-natureza e teoriaprática, destacam-se os aspectos do uso da terra e da vegetação que influenciam de modo significativo as dinâmicas das paisagens. Em conformidade com Weill e Pires Neto (2007), o uso da terra também interfere na forma e intensidade de atuação dos processos erosivos.

Nesse sentido, o objetivo principal do presente artigo foi analisar a importância do levantamento expedito do uso da terra e cobertura vegetal nas dinâmicas das paisagens de parte dos municípios de Marabá Paulista-SP e Presidente Epitácio-SP.

Cabe mencionar que a escolha da área de estudo e a relevância do tema se contextualizam no cenário frequente de degradação dos solos da região associado aos ciclos econômicos e usos da terra.

Os municípios de Marabá Paulista e Presidente Epitácio situam-se no Extremo Oeste do Estado de São Paulo (Figura 1). De acordo com o Instituto Brasileiro de Geografia e Estatística (IBGE, 2016), a área territorial de Marabá Paulista é de $919,519 \mathrm{~km}^{2}$ e sua população estimada foi de 5.524 em 2016. Já Presidente Epitácio dispõe 1.260,281 km², com cálculo de 43.718 habitantes no ano de 2016. 
Figura 1: Mapa de localização da área de estudo.

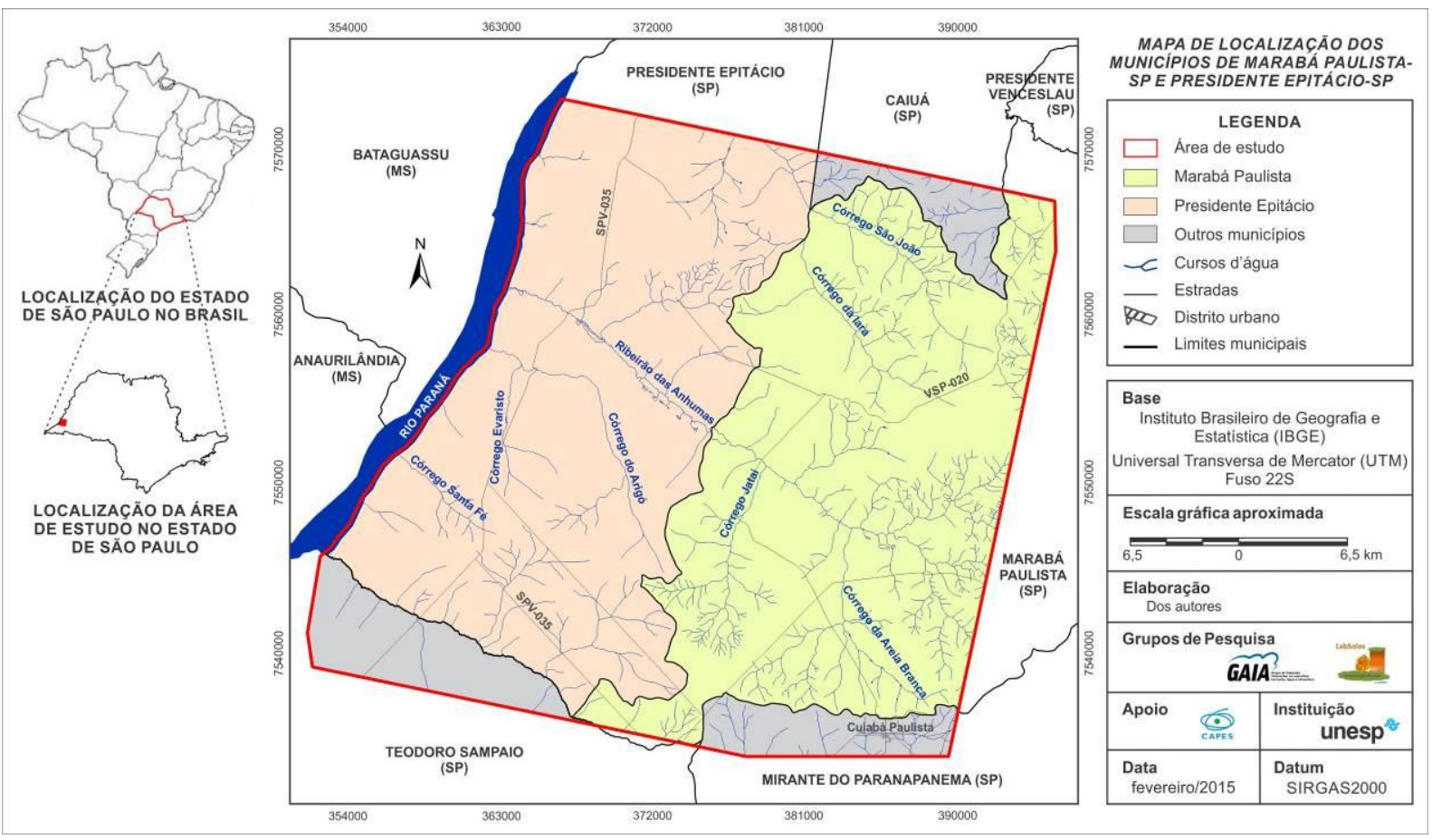

Fonte: Dos autores (2015).

\section{MATERIAIS E MÉTODOS}

O mapa de uso da terra e cobertura vegetal de parte dos municípios de Marabá Paulista-SP e Presidente Epitácio-SP na escala 1:50.000 foi elaborado a partir de duas imagens do satélite Advanced Land Observing Satellite (ALOS), sensor Advanced Visible and Near Infrared Radiometer type 2 (AVNIR-2), com resolução espacial de 10 metros, datadas de 24 de abril de 2009 e 09 de junho de 2009.

A princípio, no ArcGIS 10.2.2 ${ }^{\circledR}$, mediante as ferramentas "Build Seamlines" e "Create Referenced Mosaic Dataset", realizou-se o mosaico das referidas imagens de satélite com inserção de linha de corte na área de sobreposição. “A Linha de Corte é o elemento fundamental para mosaicar imagens. Quando há sobreposição de cenas, é possível especificar um limite entre as imagens. É necessário que esse limite seja irregular e suave nas fronteiras" (PROCESSAMENTO DIGITAL, 2016).

Posteriormente, o mosaico foi importado no Sistema de Processamento de Informações Georeferenciadas (SPRING 5.2. ${ }^{\circledR}$ ), onde ocorreu a segmentação por meio do método "Crescimento de Regiões" e a classificação supervisionada por regiões pelo classificador "Bhattacharya". "O classificador Bhattacharya, ao contrário do Isoseg que é 
automático, requer interação do usuário, através do treinamento. Neste caso, as amostras serão as regiões formadas na segmentação de imagens" (CÂMARA et al., 1996, não paginado).

A legenda foi adaptada do sistema de classificação da cobertura e do uso da terra proposto pelo Instituto Brasileiro de Geografia e Estatística (IBGE, 2013) e sua finalização gráfica foi feita no CorelDRAW $X 7^{\circledR}$.

Os cálculos das porcentagens das classes de uso da terra e cobertura vegetal ocorreram com a opção "Medidas de Classes" do SPRING 5.2.3 ${ }^{\circledR}$ e o gráfico foi feito no Excel $2013^{\circledR}$. Já os pontos cotados, os limites municipais, os cursos d'água, as estradas e os limites das propriedades rurais foram cedidos pelo IBGE (2015) na escala 1:50.000.

No mais, trabalhos de campo foram realizados objetivando atualizar as informações mapeadas, além do levantamento de pontos representativos de amostragem para auxiliar a análise da importância do uso da terra e da cobertura vegetal nas dinâmicas das paisagens do recorte de trabalho.

\section{MEIOS MORFODINÂMICOS: MEIOS ESTÁVEIS, INTERGRADES E FORTEMENTE INSTÁVEIS}

Com base no conceito de sistema, considerado "[...] um conjunto de fenômenos que se processam mediante fluxos de matéria e energia" (TRICART, 1977, p. 19) e na noção de ecossistema sistematizada por Tansley (1935) como "[...] um conjunto de seres vivos mutuamente dependentes uns dos outros e do meio ambiente no qual eles vivem" (TRICART, 1977, p. 17), Tricart (1977) propõe uma metodologia denominada de Ecodinâmica.

A Ecodinâmica refere-se à dinâmica do ambiente dos ecossistemas, em que se estabelece uma taxonomia flexível baseada na intensidade dos processos atuais. Assim, Tricart (1977) distingue três meios morfodinâmicos, os meios estáveis, intergrades e fortemente instáveis.

Os meios estáveis são caracterizados pelo predomínio da pedogênese e seguintes situações: cobertura vegetal capaz de frear os processos morfogenéticos, dissecação moderada e ausência de manifestações vulcânicas que podem desencadear processos morfodinâmicos mais ou menos catastróficos.

As pesquisas do pedólogo Erhart (1956) ressaltaram a importância da vegetação e do termo "biostasia", posteriormente substituído por Tricart (1977) por "fitoestasia", pois 
somente as plantas atuam como estabilizadoras dos fluxos de radiação e das gotas da chuva e como moderadoras do vento.

Os meios intergrades se relacionam à passagem gradual dos meios estáveis para os meios fortemente instáveis, são cambiantes e sensíveis às intervenções em escala local. Nessas circunstâncias tem-se a interferência permanente da pedogênese e da morfogênese, cujo balanço possui estreita relação com a presença da cobertura vegetal.

Nos meios morfodinâmicos fortemente instáveis, a morfogênese prevalece e são consideradas as seguintes condições e particularidades: geodinâmica interna, em especial o vulcanismo, forte instabilidade climática, degradação antrópica, fenômenos catastróficos (como corridas de lama e desmoronamentos) e ravinamentos generalizados.

A Figura 2 representa um esquema síntese dos meios morfodinâmicos discorridos por Tricart (1977), suas principais inter-relações e características:

Figura 2: Esquema síntese dos meios morfodinâmicos propostos por Tricart (1977).

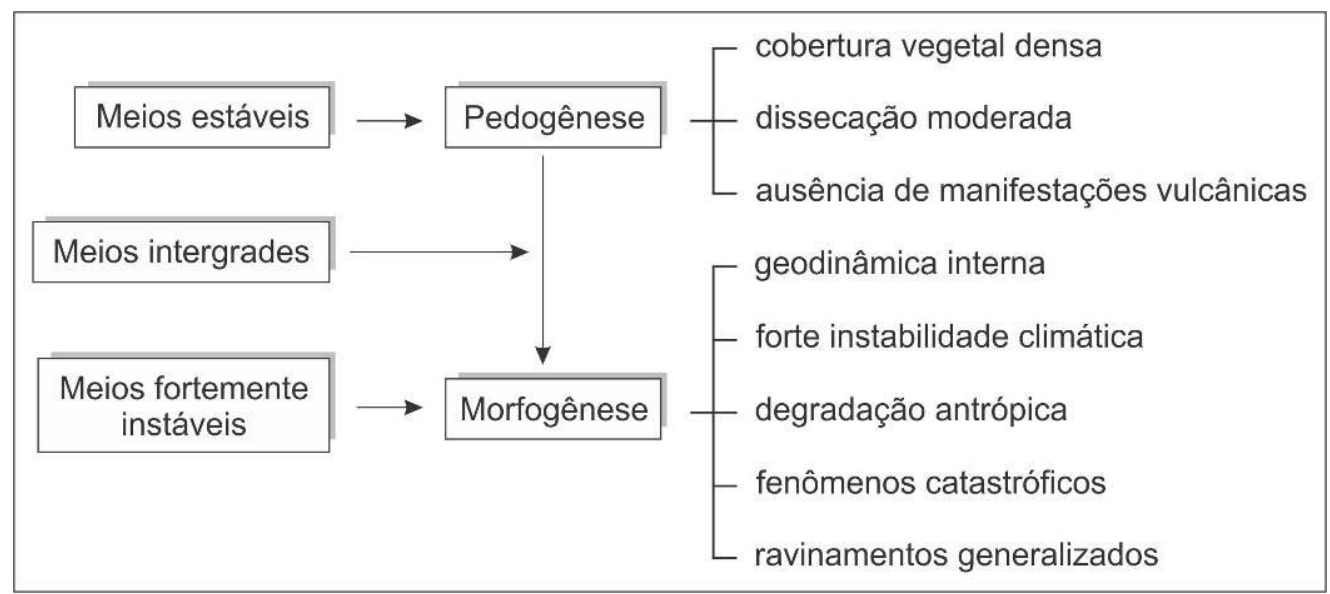

Fonte: Tricart (1977).

Elaboração: dos autores.

À vista disso, dentre os atributos que influenciam a estabilidade dos meios morfodinâmicos, destaca-se a vegetação nas dinâmicas das paisagens, principalmente, em parte de Marabá Paulista-SP e Presidente Epitácio-SP, municípios localizados em uma região evidenciada por meios morfodinâmicos fortemente instáveis pela degradação antrópica e ravinamentos generalizados, além de sulcos, voçorocas e erosões laminares. 


\section{HISTÓRICO DO USO DA TERRA E DA COBERTURA VEGETAL NA ÁREA DE ESTUDO}

Segundo Godoy (2002), os primeiros moradores no Extremo Oeste Paulista foram os índios Coroados. Em Presidente Epitácio-SP também habitavam os grupos indígenas Caiuá e Xavantes, cujas terras foram gradativamente ocupadas, no início do século $\mathrm{XX}$, diante da necessidade de construção de uma estrada de rodagem que ligasse a região, mais conhecida como "sertão nordestino", com o setor Sul do Mato Grosso (atual Estado do Mato Grosso do Sul).

No mesmo município, a facilidade de escoamento da madeira pelo rio Paraná, por intermédio do transporte fluvial, favoreceu a introdução de serrarias na década de 1940, atividade que se manteve até por volta de 1980.

Adiante, tanto em Marabá Paulista-SP quanto Presidente Epitácio-SP, ocorreu o desenvolvimento da agricultura, com o plantio de café (introduzido pelos pioneiros), seguido do algodão, melão, tomate, dentre outros produtos cultivados.

Com o acelerado extermínio das tribos indígenas e o desmatamento da cobertura vegetal original (mata) associados à construção da Estrada de Ferro Sorocabana, subsídio ao comércio de madeira e expansão das lavouras de café, o processo de povoamento se intensificou.

Monbeig (1984), partindo da cidade de São Paulo em direção ao rio Paraná, descreve as paisagens observadas:

Quando, partindo de São Paulo, toma-se um dos trens que levam até as barrancas do rio Paraná, atravessam-se umas após outras, as regiões conquistadas pelo homem. Depois do relevo de morros desmatados, próximos da capital, por exemplo na direção de Campinas, aparecem cafezais abandonados, numa topografia menos acidentada. Ainda mais longe, transposto o escarpamento de basaltos e arenitos, que limita os planaltos ocidentais, a leste, lá onde a ferrovia já não encontra obstáculos, e começa a descer lentamente no rumo do rio Paraná, atravessa-se uma paisagem na qual se alternam pastagens, mirradas plantações de café e lavouras de algodão, cujos solos trazem os sulcos da erosão bem à mostra. (MONBEIG, 1984, p. 22).

A respeito dos solos formados pelos arenitos do Grupo Bauru, Monbeig (1984) menciona os ravinamentos nas vertentes: 
2. Os solos formados pelos arenitos

Eles cobrem a maior parte da área pioneira paulista e se inscrevem na paisagem mais fortemente do que as terras roxas. Turbilhões de areia levantados pelo vento, estradas em que os caminhões encalham durante a estação seca, ravinamentos nas encostas arenosas, são visões mais freqüentes do que os belos coloridos da terra roxa sob um por-de-sol. (MONBEIG, 1984, p. 79).

Além das ravinas, estão presentes as demais feições erosivas lineares - sulcos e voçorocas - e laminares, ambas recorrentes até os dias atuais, bem como o uso da terra pela pastagem.

Com referência aos levantamentos publicados por Vitor (1975 apud Tavares, 1986) e Serra Filho et al. (1974), Boin (2000) ressalta a redução das matas no Extremo Oeste do Estado de São Paulo (Figura 3): em 1920, a maior parte da região dispunha da referida cobertura vegetal. Todavia, entre as décadas de 1920 e 1970, a vegetação natural reduziu-se à alguns fragmentos, com maior concentração na reserva do Morro do Diabo, situada no município de Teodoro Sampaio-SP, situação estendida até o ano de 2001, como demonstra a Figura 4:

Figura 3: Evolução da destruição da cobertura florestal primitiva no Oeste Paulista.

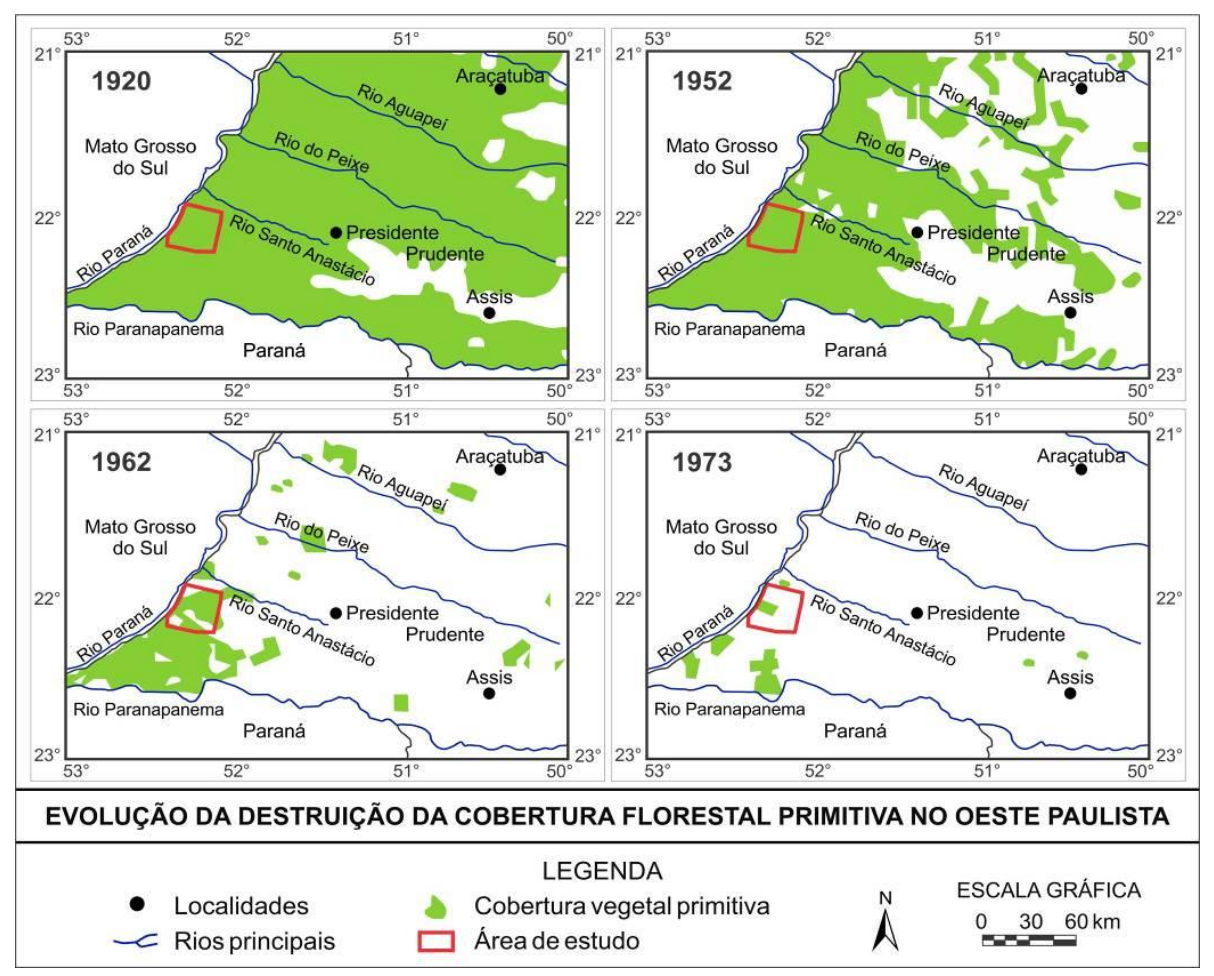

Fonte: Boin (2000).

Modificado pelos autores. 
Figura 4: Vegetação natural na região do Oeste Paulista no ano de 2001.

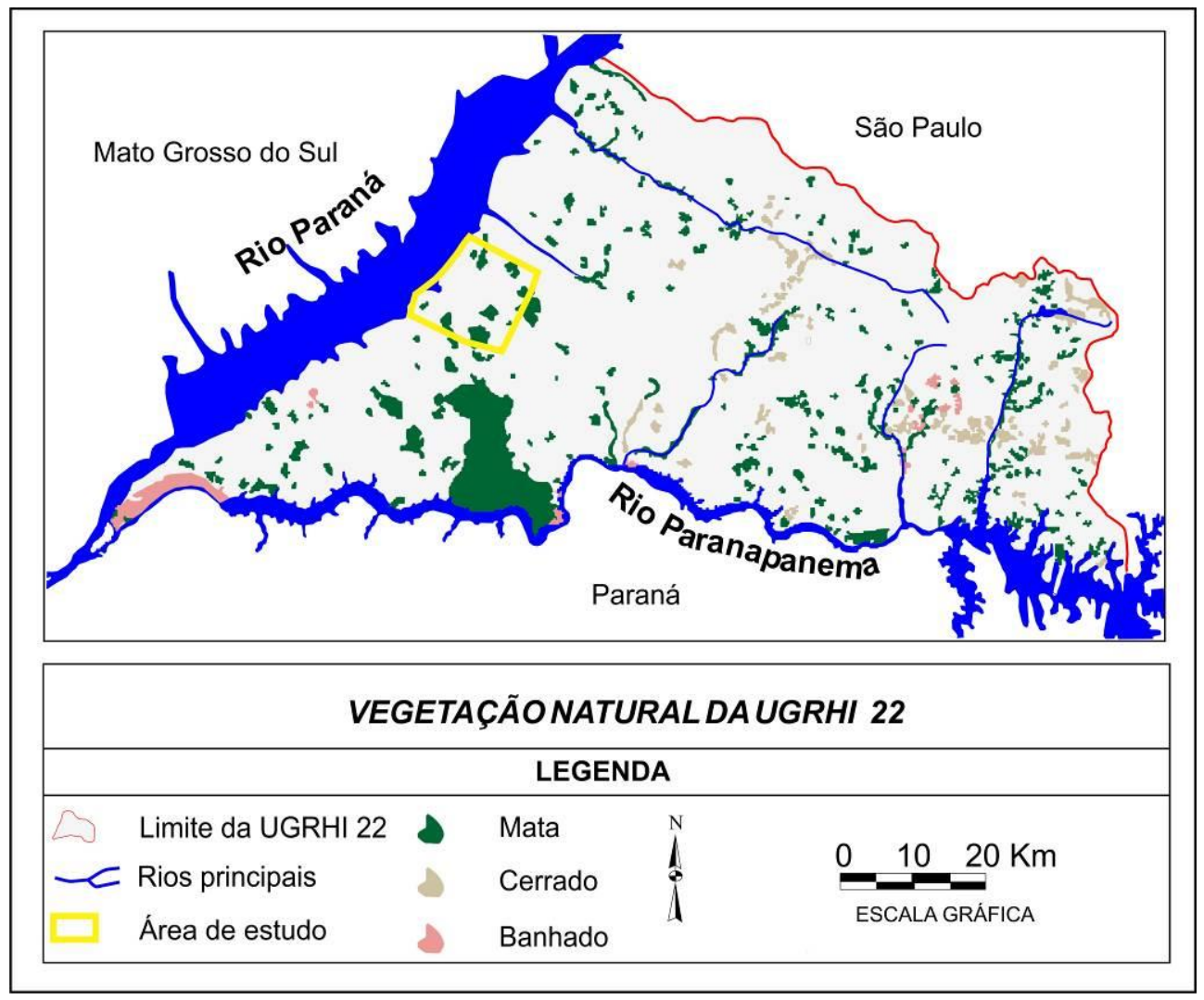

Fonte: Meneguette (2001).

Modificado pelos autores.

De acordo com Santos (2010), no presente momento histórico, em virtude das características naturais dos solos, isto é, solos arenosos e vulneráveis às manifestações erosivas laminares e lineares, e da retirada parcial ou total da vegetação, inclusive, as matas ciliares próximas aos cursos d'água, estão relacionadas ao declínio da produção agrícola e ao predomínio da pecuária em Presidente Epitácio-SP. Tais condições também se apresentam em Marabá Paulista-SP.

Ademais, na área estudada, a atividade canavieira vem aumentando no decorrer dos anos, conforme aponta o trabalho de Braido (2015), ao pesquisar a expansão da cana de açúcar na bacia hidrográfica do rio Paranapanema-PR/SP (Figura 5). 
Figura 5: Área explorada pelo cultivo da cana de açúcar entre 2003 a 2012 Unidade de gestão Pontal do Paranapanema-SP.

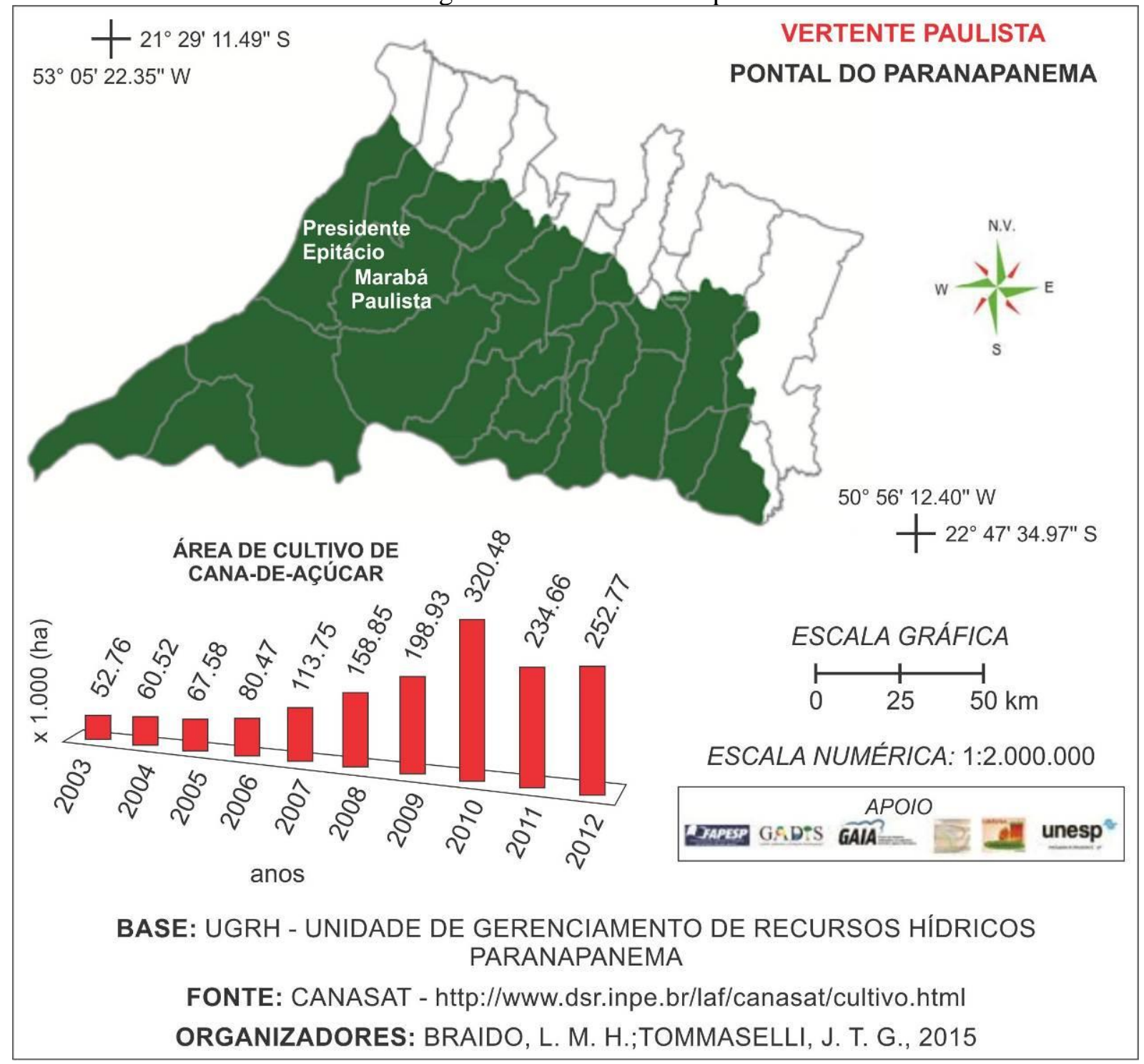

Fonte: Braido (2015).

Modificado pelos autores.

\section{RESULTADOS E DISCUSSÃO}

Com o intuito de analisar a relevância dos aspectos referentes ao uso da terra e à cobertura vegetal nas dinâmicas das paisagens da área de estudo, foi elaborado o mapa de uso da terra e cobertura vegetal de parte dos municípios de Marabá Paulista-SP e Presidente Epitácio-SP (Figura 6). 
Figura 6: Mapa de uso da terra e cobertura vegetal de parte dos municípios de Marabá Paulista-SP e Presidente Epitácio-SP.

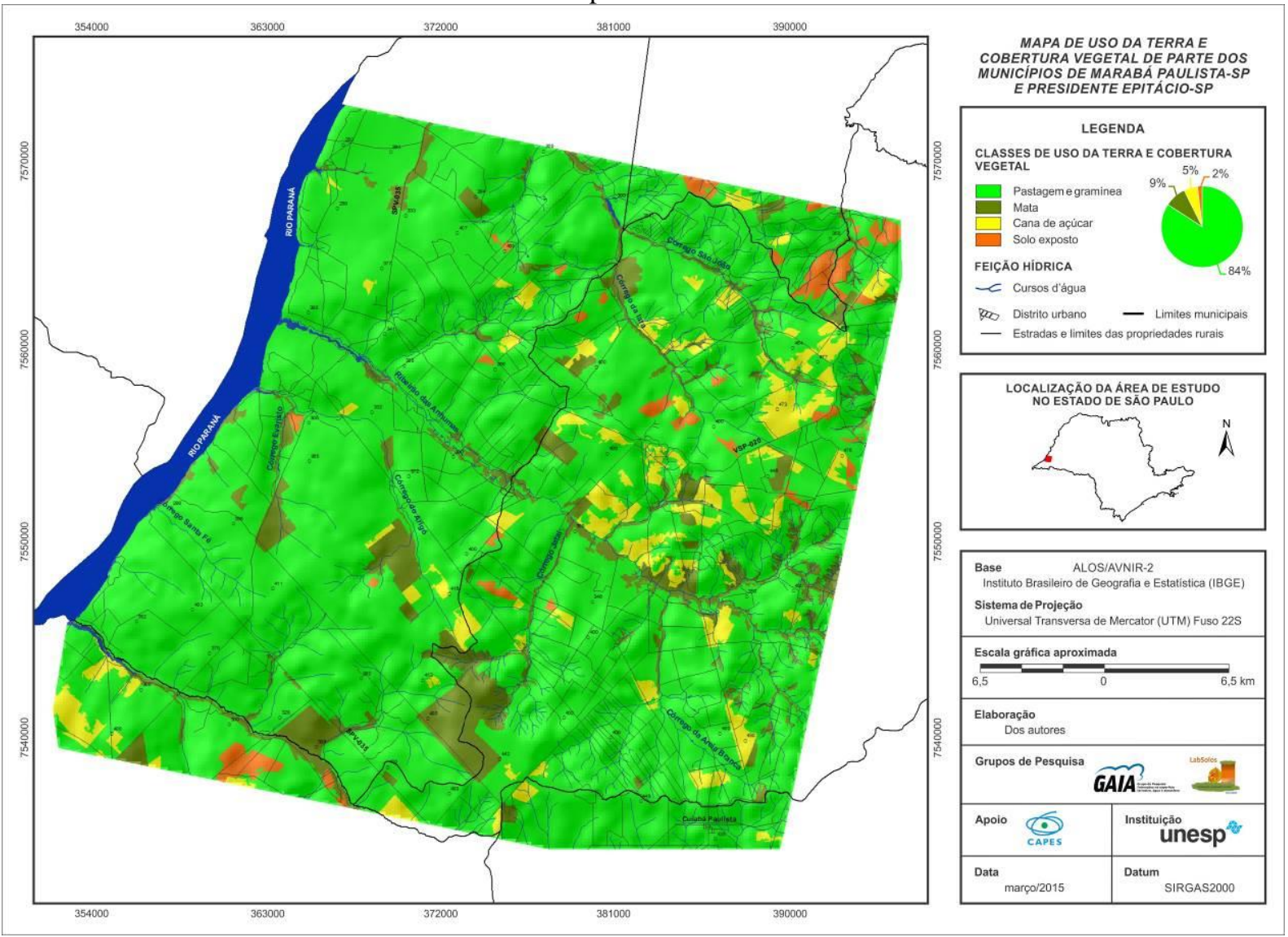

Elaboração: dos autores.

Acerca da configuração espacial das classes de uso da terra e cobertura vegetal, a pastagem e a gramínea prevalecem, com 84\%. As matas (9\%) são caracterizadas por ciliares e reflorestadas e, em seguida, têm-se o cultivo de cana de açúcar (5\%) e solo exposto (2\%).

Haja vista que os documentos cartográficos se constituem uma ferramenta de análise e não uma finalidade em si mesma, a partir do mapa realizado, quatro pontos representativos de amostragem foram caracterizados, denominados de Pontos 1, 2, 3 e 4.

Ponto 1. Matas reflorestadas

O Ponto 1 é representado pela ocorrência de matas reflorestadas (Figura 7), em que as declividades são suaves (não ultrapassam 5\%), influenciando na estabilidade dos meios morfodinâmicos e na ausência de manifestações erosivas. 
Figura 7: Ponto 1 - matas reflorestadas.

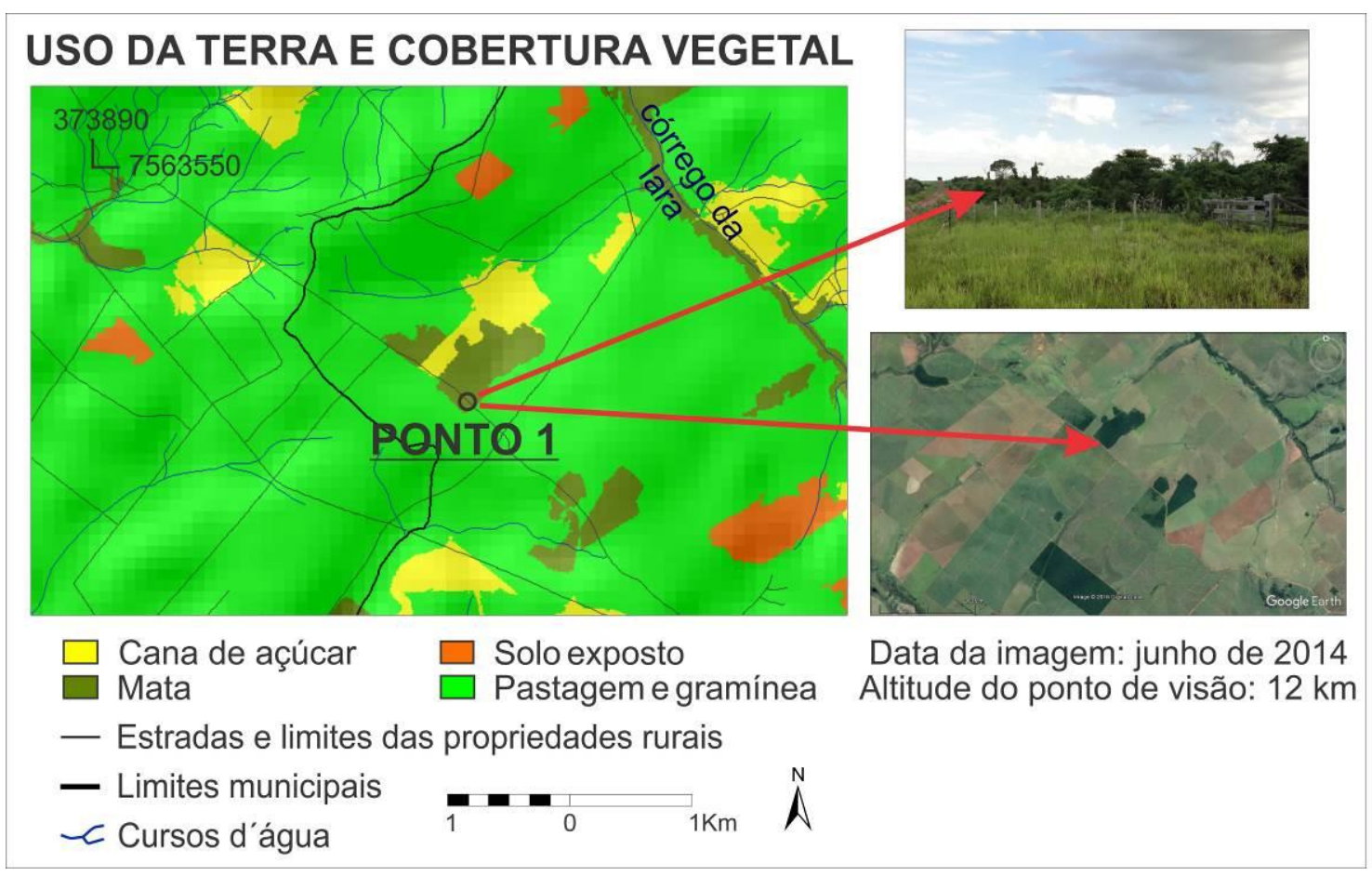

Elaboração: dos autores.

Foto: dos autores, trabalho de campo, fevereiro de 2014. Imagem: Google Earth ${ }^{\circledR}$.

Sob esse contexto, vale destacar o cercamento da área que evita o acesso do gado presente nas proximidades e o seu consequente pisoteio, permitindo o crescimento da cobertura vegetal.

Ponto 2. Cana de açúcar

As paisagens do Ponto 2 caracterizam-se por solos desenvolvidos (mais de 150 centímetros de profundidade) em colinas amplas suavemente onduladas, cujas declividades são abaixo de $5 \%$.

Tais atributos têm favorecido a expansão do cultivo de cana de açúcar (Figura 8), inclusive em setores de gramínea, conforme observou-se nas imagens ALOS/AVNIR-2, datadas de 2009 (utilizadas para a elaboração do mapa de uso da terra e cobertura vegetal), em comparação aos trabalhos de campo feitos nos anos de 2014 e 2015. 
Figura 8: Ponto 2 - cana de açúcar.

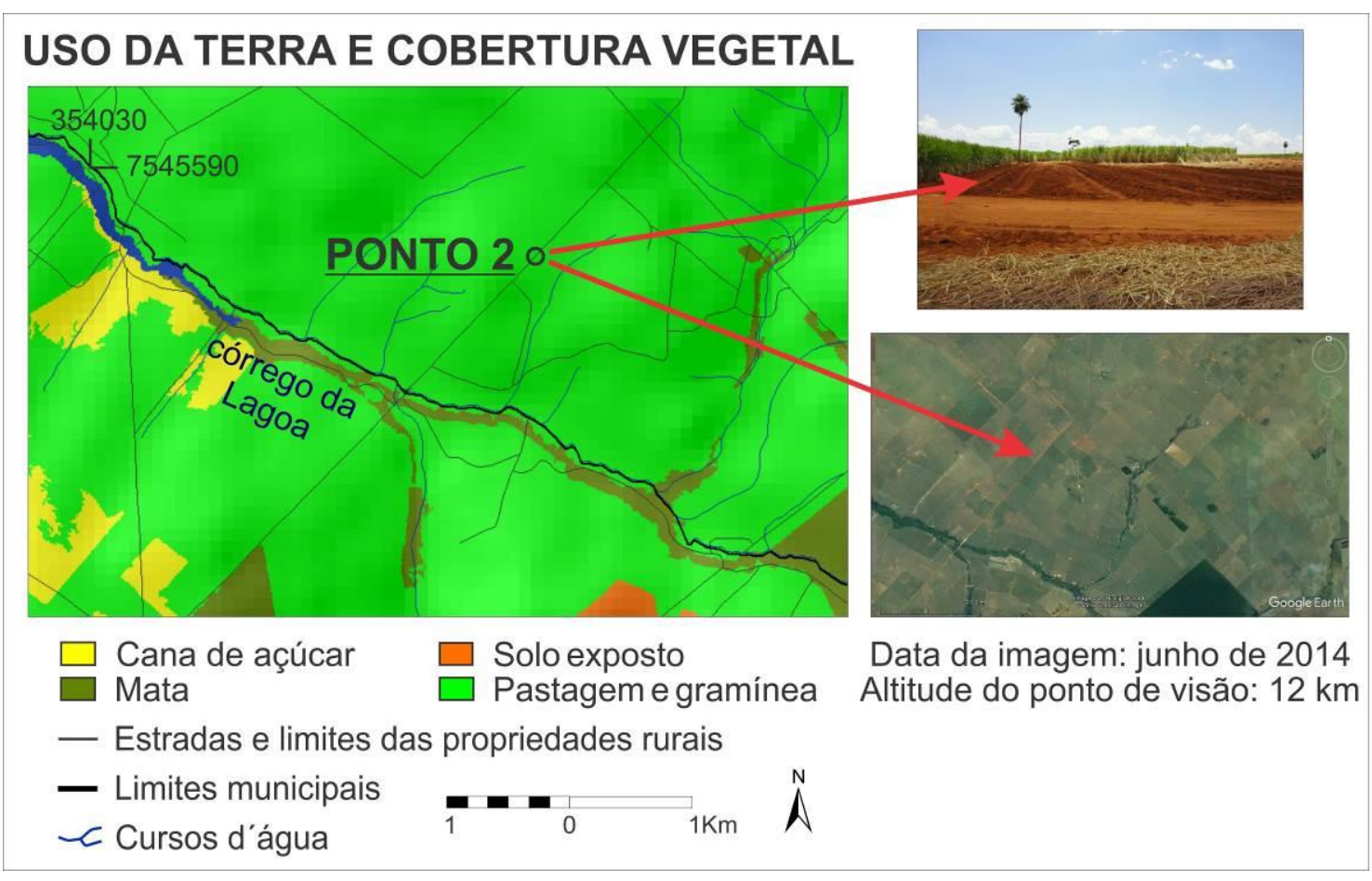

Elaboração: dos autores.

Foto: dos autores, trabalho de campo, outubro de 2015. Imagem: Google Earth $^{\circledR}$.

Mesmo com a implantação de bacias coletoras nas margens das estradas de terra para captar e armazenar as águas pluviais e reter os sedimentos, a jusante do Ponto 2 se situa o córrego da Lagoa (afluente do rio Paraná), sem matas ciliares, e que se encontra assoreado pelos sedimentos advindos de montante (Figura 9).

Figura 9: Córrego da Lagoa assoreado.

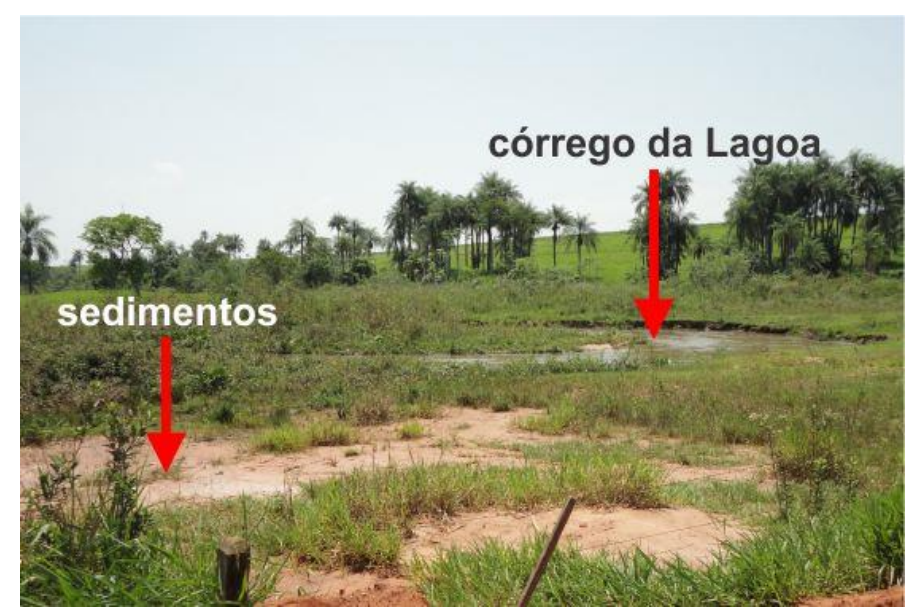

Foto: dos autores, trabalho de campo, outubro de 2015. 
Perante tais circunstâncias, os meios morfodinâmicos são intergrades, pois a pedogênese ocorre com a presença da cana de açúcar, no entanto, a morfogênese é mais intensa, visto o processo de assoreamento no fundo de vale.

\section{Ponto 3. Solo exposto}

No Ponto 3, o uso da terra é o solo exposto (Figura 10), cenário temporário para posterior atividade canavieira, segundo observou-se em trabalhos de campo realizados.

Figura 10: Ponto 3 - solo exposto.

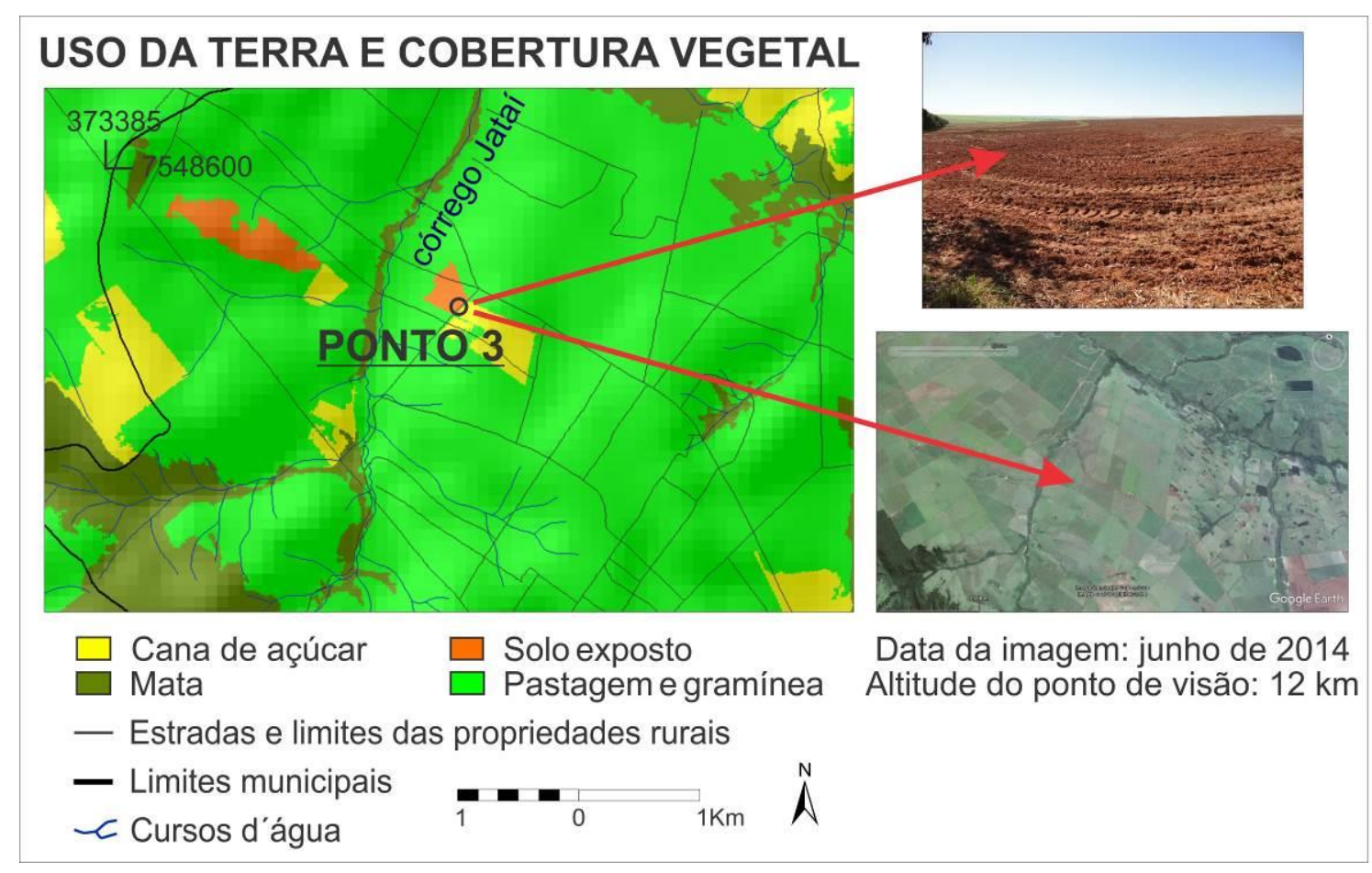

Elaboração: dos autores.

Foto: dos autores, trabalho de campo, outubro de 2015. Imagem: Google Earth $^{\circledR}$.

A superfície, mesmo ao permanecer descoberta periodicamente e com declividades menores que 5\%, está vulnerável à ação do splash, ou seja, à fase inicial da dinâmica erosiva, em que os sedimentos são removidos, transportados (na área de estudo, especialmente pela precipitação) e depositados a jusante.

Dessa forma, os meios morfodinâmicos são intergrades com tendência à fortemente instáveis. 
Ponto 4. Pastagem e gramínea

No Ponto 4 observou-se o predomínio da gramínea associada à pastagem (Figura 11) nas colinas amplas suavemente onduladas, com declividades inferiores a 5\%. Apesar da construção de terraços nas propriedades rurais, isto é, uma prática mecânica de conservação dos solos para conter a erosão hídrica, os mesmos não apresentam manutenção e foram rompidos pela atividade pastoril.

Nessa conjuntura, o pisoteio do gado acelera a compactação do solo em formato de caminhos, promovendo a diminuição da infiltração das águas das chuvas, a convergência do escoamento superficial e o incremento do fluxo linear.

Figura 11: Ponto 4 - pastagem e gramínea.

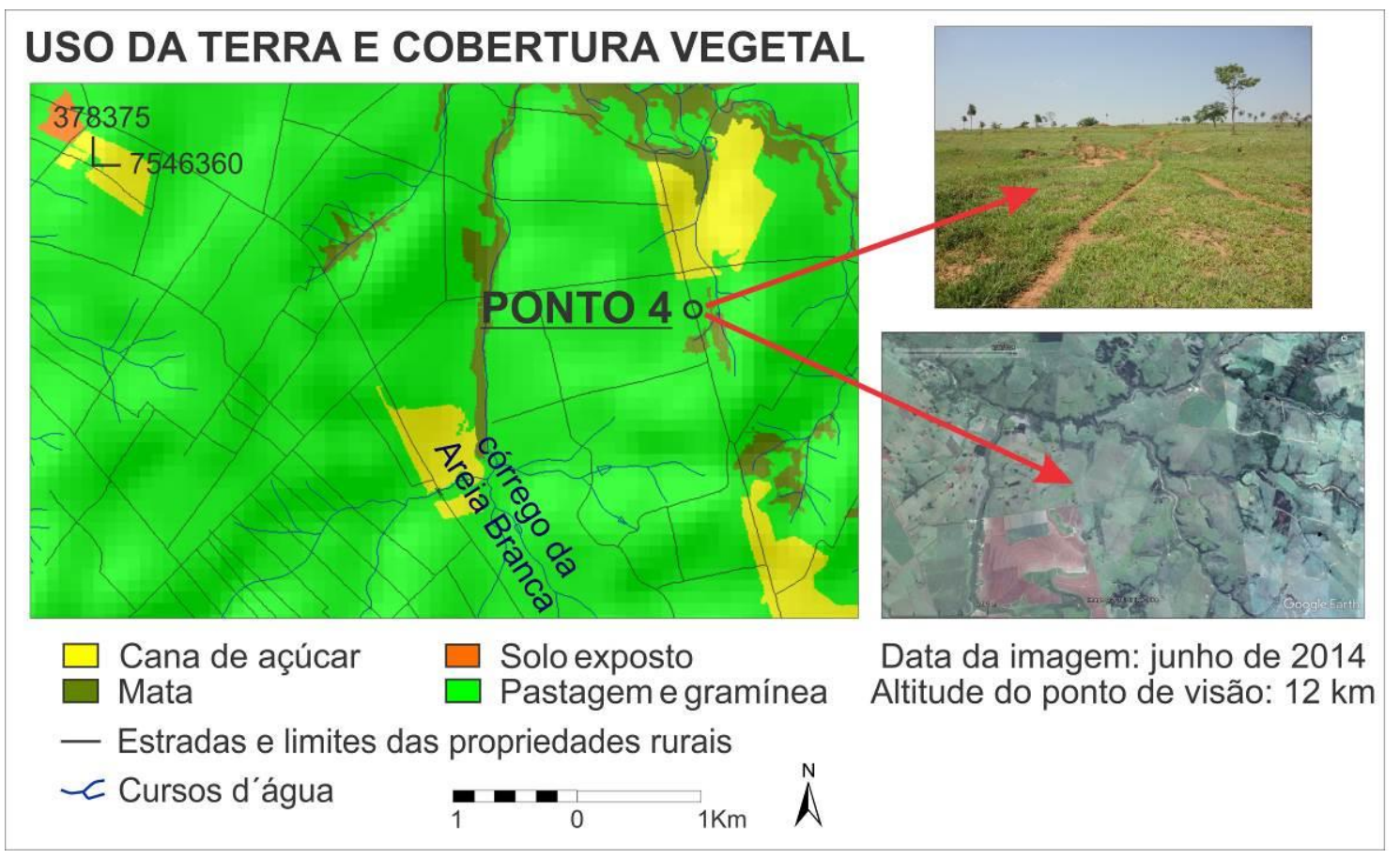

Elaboração: dos autores.

Foto: dos autores, trabalho de campo, outubro de 2015. Imagem: Google Earth $^{\circledR}$.

Por conseguinte, os meios morfodinâmicos são fortemente instáveis, sendo este tipo de processo erosivo um dos mais recorrentes na região do Extremo Oeste Paulista. 


\section{CONSIDERAÇÕES FINAIS}

Diante das considerações realizadas, o presente texto objetivou analisar a importância do levantamento expedito do uso da terra e cobertura vegetal nas dinâmicas das paisagens de parte dos municípios de Marabá Paulista-SP e Presidente Epitácio-SP.

Para tal, foi elaborado o mapa de uso da terra e cobertura vegetal, o qual subsidiou a realização de trabalhos de campo, em que quatro pontos representativos de amostragem foram caracterizados. Cabe mencionar que as atividades em campo também foram relevantes no sentido de verificar e atualizar as informações mapeadas em trabalhos de gabinete.

De modo geral, o recorte de estudo apresentou setores com matas ciliares e remanescentes, solo exposto para posterior plantio de cana de açúcar, atividade canavieira e, principalmente, gramínea com a finalidade de pastagem. Tais classes, em interação com os demais aspectos que compõem as paisagens, refletem-se em meios estáveis, integrades e fortemente instáveis.

Além disso, em consonância com o quadro erosivo da região do Extremo Oeste do Estado de São Paulo, a área de estudo encontra-se vulnerável ao desenvolvimento da erosão hídrica.

Enfim, o trabalho pode contribuir ao orientar a implantação de medidas conservacionistas nos meios estáveis e técnicas de recuperação de áreas degradadas nos meios fortemente instáveis. Em relação aos meios intergrades, recomenda-se, a princípio, analisar o balanço pedogênese/morfogênese para, posteriormente, indicar quais práticas (conservação ou recuperação) poderão ser utilizadas.

\section{AGRADECIMENTOS}

À Coordenação de Aperfeiçoamento de Pessoal de Nível Superior (CAPES) pelo auxílio ao desenvolvimento da pesquisa.

\section{REFERÊNCIAS}

BOIN, M. N. Chuvas e Erosões no Oeste Paulista: Uma Análise Climatológica Aplicada. 2000. 264 p. Tese (Doutorado em Geociências e Meio Ambiente) - Instituto de Geociências e Ciências Exatas, Universidade Estadual Paulista, Rio Claro, 2000. 
BRAIDO, L. M. H. Geocomplexo: Interação de elementos naturais e sociais - Produção e expansão da cana-de-açúcar na bacia hidrográfica do rio Paranapanema - PR / SP. 2015. 182 p. Tese (Doutorado em Geografia) - Faculdade de Ciências e Tecnologia, Universidade Estadual Paulista, Presidente Prudente, 2015.

CÂMARA, G.; SOUZA, R. C. M.; FREITAS, U. M.; GARRIDO, J.; MITSUO II, F. SPRING: Integrating remote sensing and GIS by object-oriented data modelling. Computers \& graphics, New York, v. 20, n. 3, p. 395-403, may./jun. 1996.

ERHART, H. La theorie bio-rexistesique et les problemes biogeographiques et paleobiologiques. Soc. Biogéogr. de France, CNR (288), p. 43-53, 1956.

GODOY, B. História de Presidente Epitácio. Presidente Epitácio: [s.n.], 2002.

INSTITUTO BRASILEIRO DE GEOGRAFIA E ESTATÍSTICA (IBGE). Manual Técnico de Uso da Terra. 3. ed. Rio de Janeiro: IBGE, 2013.

INSTITUTO BRASILEIRO DE GEOGRAFIA E ESTATÍSTICA (IBGE). Disponível em: <http://www.downloads.ibge.gov.br>. Acesso em: 28 maio 2015.

INSTITUTO BRASILEIRO DE GEOGRAFIA E ESTATÍSTICA (IBGE). Disponível em: <http://www.cidades.ibge.gov.br>. Acesso em: 19 dezembro 2016.

MENEGuette, A. A. C. Atlas Interativo do Pontal do Paranapanema: uma contribuição à Educação Ambiental. 2001. 190 p. Tese (Livre Docência em Cartografia) - Faculdade de Ciências e Tecnologia, Universidade Estadual Paulista, Presidente Prudente, 2001.

MONBEIG, P. Pioneiros e fazendeiros de São Paulo. São Paulo: Hucitec, Polis, 1984.

PROCESSAMENTO DIGITAL. Disponível em: <http://www.processamentodigital.com.br>. Acesso em: 19 dezembro 2016.

SANTOS, R. Meio ambiente e qualidade de vida na Estância Turística de Presidente Epitácio - São Paulo. 2010. 374 p. Dissertação (Mestrado em Geografia) - Faculdade de Ciências e Tecnologia, Universidade Estadual Paulista, Presidente Prudente, 2010.

SERRA FILHO, R.; CAVAlli, A. C.; GUILlaumON, J. R.; CHIARINI, J. V.; NOGUEIRA, F. P.; IVNAKO, C. M.; BARBIEIRI, J. L.; DONZELI, P. L.; COELHO, A. G. S.; BITTENCOURT, I. Levantamento da cobertura vegetal natural e do reflorestamento no Estado de São Paulo. Boletim Técnico do Instituto Florestal, São Paulo, v. 11, p. 1-53, ago. 1974.

TANSLEY, A. G. The use and abuse of vegetational concepts and terms. Ecology, v. 16, n. 3, p. 284-307, jul. 1935. 
TAVARES, A. C. A erosão dos solos no contexto da análise ambiental: o exemplo do alto curso do rio São José dos Dourados. 1986. 254 p. Tese (Doutorado em Geografia Física) Faculdade de Filosofia, Letras e Ciências Humanas, Universidade de São Paulo, São Paulo, 1986.

TRICART, J. Ecodinâmica. Rio de Janeiro: IBGE, Diretoria Técnica, SUPREN, 1977. 91 p. WEILL, M. A. M.; PIRES NETO, A. G. Erosão e Assoreamento. In: SANTOS, R. F. (Org.). Vulnerabilidade Ambiental. Brasília: MMA, 2007. p. 39-58. 